\title{
La analogía negativa en la morfología del participio de pasado: el caso excepcional de roto
}

\author{
Negative analogy in past participle morphology: The exceptional \\ case of roto
}

\author{
Jason Doroga \\ Ouachita Baptist University \\ dorogaj@obu.edu
} ORCID iD: https://orcid.org/0000-0003-3782-2588

Fernando Tejedo-Herrero

University of Wisconsin-Madison

lftejedo@wisc.edu

ORCID iD: https://orcid.org/0000-0002-3615-3047

RESUMEN: Este artículo analiza el inesperado cambio en el uso de las variantes del participio perfectivo de romper. El examen de los datos refleja el triunfo de roto en detrimento de rompido, variante aceptada en la norma culta hasta el siglo XVIII. Tras analizar los posibles factores del cambio, proponemos el concepto de analogía negativa para describir la progresiva devaluación sociolingüística que experimentó rompido por asociación con otros participios analógicos históricamente estigmatizados. La propuesta se apoya también en el caso afín de proveer, cuyo desarrollo expone las divergencias en el proceso de codificación de la variedad estándar.

Palabras clave: participio de pasado, morfología, analogía, hipercorrección, estandarización.

ABSTRACT: This paper analyzes the unexpected change in the form of the past participle of the verb romper in the history of Spanish. We examine the factors that contributed to the triumph of roto, to the detriment of rompido, the form accepted in the standard register until the 18th century. We propose the concept of negative analogy to account for the social devaluation of the form rompido as a result of its association with other historically stigmatized analogical participles. To support our proposal, we also consider the case of proveer, whose historical development demonstrates the vicissitudes of the standardization process.

Keywords: past participle, morphology, analogy, hypercorrection, standardization. 


\section{INTRODUCCIÓN}

Este trabajo ofrece una revisión histórica de la forma de participio rizotónica roto y las circunstancias que permitieron su imposición sobre la forma arrizotónica rompido, más común y aceptada hasta el siglo XVIII, en función de participio perfectivo. Como se desprende de la lectura de manuales y gramáticas, la regularización de las formas de participio etimológico y su eliminación en función verbal ha sido la nota predominante en la historia del español (cfr. Alvar y Pottier, 1983: 279-283; García de Diego, 1961: 253-254; Lapesa, 2000: 774-776; Lloyd, 1993: 498-501; Penny, 2006: 269-271)1.

La regularización de las formas de participio etimológicas ha seguido una de tres posibles historias. La primera, y más representativa, ha sido la pérdida temprana de la forma fuerte durante la época del romance castellano (o con anterioridad) a favor de una forma analógicamente creada, arrizotónica, y la única actualmente aceptada en las variedades estándares: TRAHERE 'traer', participio TRACTUM > trecho (español antiguo), traído (español actual); COQUERE 'cocer', participio COCTUM $>$ cocho (español antiguo), cocido (español actual), etc. La segunda línea evolutiva corresponde a algunos verbos cuyos participios etimológicos concurren con los analógicos: juntado/junto, teñidoltinto, torcido/tuerto, soltado/suelto, maltraídol maltrecho, etc. En estos casos de duplicación de formas de participio es típica la división de funciones, asentando las verbales en la forma analógica (v. gr., He secado/*seco el plato) y las adjetivales o nominales en la forma etimológica ( $v$. gr., Un plato seco/*secado) ${ }^{2}$. Por último, la tercera vía de desarrollo reúne verbos con dos formas de participio, uno etimológico y otro analógico, que se admiten en las mismas estructuras gramaticales. No son muchos los verbos que aceptan participios duplos de acuerdo con la lista completa en la Nueva gramática de la lengua española ${ }^{3}$ : elegir (elegidolelecto); freír (freídolfrito); imprimir: (imprimidol impreso); prender (prendido/preso) y proveer (proveído/provisto) (Real Academia Española y Asociación de Academias de la Lengua Española, 2009: 244) ${ }^{4}$. En suma, la regularización de las formas rizotónicas en función verbal ha sido común

\footnotetext{
${ }^{1}$ Siguiendo la tradición gramatical española, empleamos el término 'participio etimológico' para designar un participio que carece del morfema /-do/ ( $v . g r$. , RUPTUS $>$ roto, FACTUM $>$ hecho, PRE(HE) NSUM $>$ preso). Empleamos el término 'participio analógico' para designar un participio con el morfema /-do/. Sin embargo, hay otros términos en la crítica para referirse a la forma sin /-do/ (por ejemplo, 'participio trunco', 'participio fuerte') (Lapesa, 1981; Laurent, 1999; Bosque, 1999).

2 Para el tratamiento de los usos verbales y usos adjetivales de los participios puede consultarse Wasow (1977), Embick (2004) y Sleeman (2014).

${ }^{3}$ Cabe señalar que la Real Academia Española admite las dos formas, tanto en construcciones verbales como adjetivales, a pesar de "notables diferencias en su extensión y en su uso" (Real Academia Española y Asociación de Academias de la Lengua Española, 2009: 244).

${ }^{4}$ Debe puntualizarse que en el caso de prendido/preso: "No se recomienda, en cambio, el uso de preso en los tiempos compuestos (Los han preso) y se prefiere el participio regular prendido" (Real Academia Española y Asociación de Academias de la Lengua Española, 2009: 245).
} 
en la historia del español y, en general, de las lenguas románicas ${ }^{5}$. Todo ello pone de relieve casos de covariación de formas de participio en que se impone la forma rizotónica en funciones de participio, como el representado por romper (roto/rompido, participio RUPTUS). Es este carácter excepcional el que llamó la atención de Malkiel, quien comenta: "la cristalización de roto en español y su larga resistencia, coronada de cierto éxito, a un rival tan temible como rompido merece cierta atención" (1993: 312). Dejando al margen el estudio de González Pérez (2008), de enfoque lexicográfico, y la propuesta de Malkiel, basada en la semántica y el fonosimbolismo, se encuentran contadas alusiones a posibles tendencias en el comportamiento sintáctico (Bello, 1887 [1847] en torno a roto/rompido y Real Academia Española (1973) en relación con el caso de provisto/proveído).

El presente estudio tiene por objetivo retomar la escasa atención que ha recibido este fenómeno y proponer un nuevo acercamiento al desarrollo de los participios de romper. Al análisis de las formas participiales de romper hemos incorporado las del verbo proveer (< PROVIDËRE, participio PROVISUS), verbo este último que comparte con roto una historia similar en cuanto al desarrollo de una doble posibilidad morfológica de participio (provisto y proveído), aunque, como se comproborá, proveer presenta una codificación dispar, pues la Academia acepta, en principio, ambas formas en funciones verbales y adjetivales. Con este propósito general, nos valemos del estudio de corpus y del tratamiento que estos verbos han recibido en la tradición gramatical. El análisis de la evidencia textual demostrará que, por un lado, las formas analógicas (rompido y proveído) dominaron en índices de frecuencia desde época temprana a las formas etimológicas (roto y provisto) en función de participio perfectivo hasta el fin del siglo XVII, momento en que las formas de participio etimológico, en contra de la tendencia común y de uso hasta el momento, aumentan drásticamente su presencia en la documentación en función de participio perfectivo. Por otro lado, el repaso de la tradición gramatical revela que el cambio abrupto en la documentación no encuentra apoyo en una posible imposición institucional, prescriptivista, pues hasta comienzos del siglo pasado la Academia admitía la duplicidad de participios para ambos verbos. En ausencia de evidencia positiva que explique el cambio, y tras evaluar las propuestas de Malkiel (1993) y Bello (1887 [1847]), y explicaciones ancladas en la coherencia morfológica (Maiden, 2018), se propone una alternativa de explicación centrada en lo que denominamos efectos de la "analogía negativa" que resultó en el rechazo de uso de las formas analógicas rompido y proveído (por asociación 'negativa' con otros participios analógicos socialmente marcados). Como se comprobará, la codificación de esta norma de uso en el español actual ha sido asimétrica, pues la forma rompido siguió la historia de los participios que no se han aceptado en

5 La excepción a esta corriente niveladora sería el sardo, en que los verbos de la segunda conjugación son principalmente rizotónicos (Maiden, 2016: 507). 
la lengua estándar, mientras que la forma proveído, a pesar de su baja frecuencia de uso, sigue siendo una forma viable, aunque poco usada.

El contenido del artículo se divide en cuatro partes. En la primera parte exponemos la distribución de los participios de romper y proveer desde el siglo XIII hasta el XIX. En la segunda comentamos un apunte historiográfico de la clasificación de los participios de romper y proveer en las principales gramáticas tanto académicas como no académicas desde el siglo XV con el fin de rastrear una posible influencia prescriptivista en el cambio radical que el análisis de corpus muestra a partir del siglo XVIII. En la tercera parte, analizamos las hipótesis de corte sintáctico (Bello, 1887 [1847]) y fonológico-semántico (Malkiel, 1993) junto con otros posibles análisis morfológicos en el desarrollo diacrónico del participio (Maiden, 2018) en torno al declive abrupto en la documentación de las formas rompido y proveído. Por último, en la cuarta parte, a la luz de la evidencia presentada, avanzamos una hipótesis de trabajo alternativa en la que, para entender mejor el proceso de la marginalización de las formas regulares, subrayamos los efectos de la analogía en la morfología del participio.

\section{LA VARIACIÓN HISTÓRICA ENTRE LOS PARTICIPIOS ETIMOLÓGICOS Y ANALÓGICOS}

\subsection{Metodología y recopilación de datos}

El objetivo de esta sección es ofrecer un panorama del uso de las formas analógicas rompido y proveído frente a las formas etimológicas roto y provisto a lo largo de la historia. Con ese propósito, se realizó una búsqueda de las formas de los participios rompido, roto, proveído y provisto de los siglos XIII a XIX en el CORDE $E^{6}$. Se extrajeron 7525 casos de participio del verbo romper y otros 3086 casos de proveer. La distribución de uso por siglo de cada variante de romper, se incluye en el gráfico 1.

El gráfico muestra el arraigo de la forma analógica de rompido desde el siglo XIII en porcentajes que aumentan y se mantienen hasta el siglo XV. El descenso general con respecto al uso de roto se inicia en el siglo XVI, continúa más pronunciadamente en el siglo XVII y despunta abruptamente en el siglo XVIII (un 6,5\% de los casos documentados) hasta casi desaparecer en el siglo XIX con tan solo una representación del 1,6 \% de los más de dos mil casos recogidos en el CORDE.

${ }^{6}$ Para la variación ortográfica de proveído y provisto se tuvieron en cuenta las variantes con v/u (-vei-, -uei-, -vey-, -uey-; -vis- y -uis-). Del mismo modo, para el cómputo de formas de participio de romper se incluyeron las variantes con $r-, r r-,-m-$ y -n- (rom-, ron-, rrom-, rron-). 


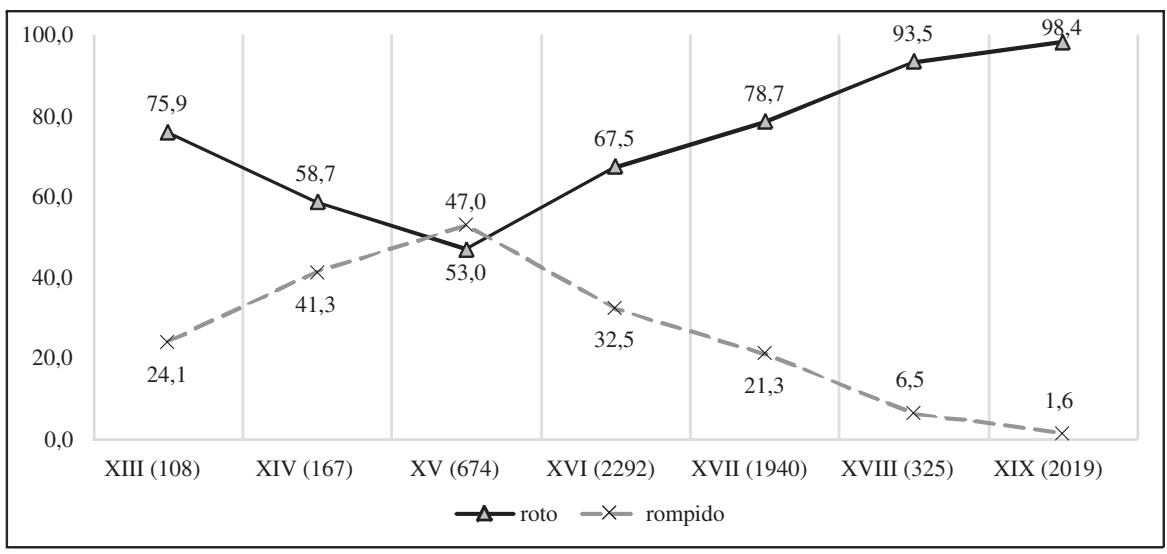

GRÁFICO 1.-Porcentaje de uso de roto y rompido, siglos XIII a XIX ${ }^{7}$.

El empleo de las formas de participio del verbo proveer, como refleja el gráfico 2, es distinto, aunque su fase final muestra un punto en común con el desarrollo delineado para rompido/roto. De acuerdo con la documentación, proveído es la única variante documentada hasta prácticamente el siglo XVI. Destaca su incorporación temprana en textos orientales de la Península Ibérica, a juzgar por los primeros casos en textos navarro-aragoneses del siglo XIII, y su establecimiento firme desde el siglo XIV hasta el siglo XVIII, momento en que su índice de frecuencia desciende drásticamente. En términos numéricos, de un $97 \%$ de los 500 casos documentados de proveído en el siglo XVII se pasa al siglo XVIII, en el que tan solo el $26 \%$, de los más de 200 casos estudiados, corresponde a esta variante. Por su parte, la presencia de provisto en textos castellanos es prácticamente excepcional hasta el siglo XV y muy modesta en los siglos XVI y XVII (en contraste con la frecuencia de uso de proveído) ${ }^{8}$. Como se acaba de indicar, no es hasta el siglo XVIII cuando provisto aventaja en la frecuencia de uso, periodo en el que su preferencia en los textos se catapulta a

${ }^{7}$ La cifra entre paréntesis tras cada siglo se refiere al número de casos examinados. En los pocos casos en que la obra se compuso entre dos siglos (p. ej.: Relación de las cosas sucedidas en la corte de España desde 1599 hasta 1614), se ha asignado al siglo con mayor número de años durante su creación. Este criterio no incide en la evolución general de las tendencias presentadas.

${ }^{8}$ Es importante notar que el caso señero del siglo XIV proviene de una traducción de un autor aragonés, Fernández de Heredia ("o apres de andar çercando aquello que no auiemos prouisto en el primer nuestro consello" [c1384-96, Fernández de Heredia, Traducción de Tucídides]). Igualmente, los dos casos a finales del siglo XV se incluyen, uno, en un documento notarial (¿quizás compuesto por un notario aragonés?) en el que Fernando, el Católico, escribe al rey de Nápoles ("teniendo ya prouisto dar a aquella otras tierras en lugar de aquellas" [1484, Fernando de Aragón al rey de Nápoles]); y otro, en la Gramática castellana de Nebrija en un comentario metalingüístico que se tratará en la sección sobre codificación: "de veer visto: aunque su compuesto proveer no hizo provisto sino proveido. de escrivir escripto” (1492, Nebrija, Gramática castellana). 
un ritmo directamente proporcional al que desciende proveído. Esta inversión en las tendencias se muestra en el gráfico 2 :

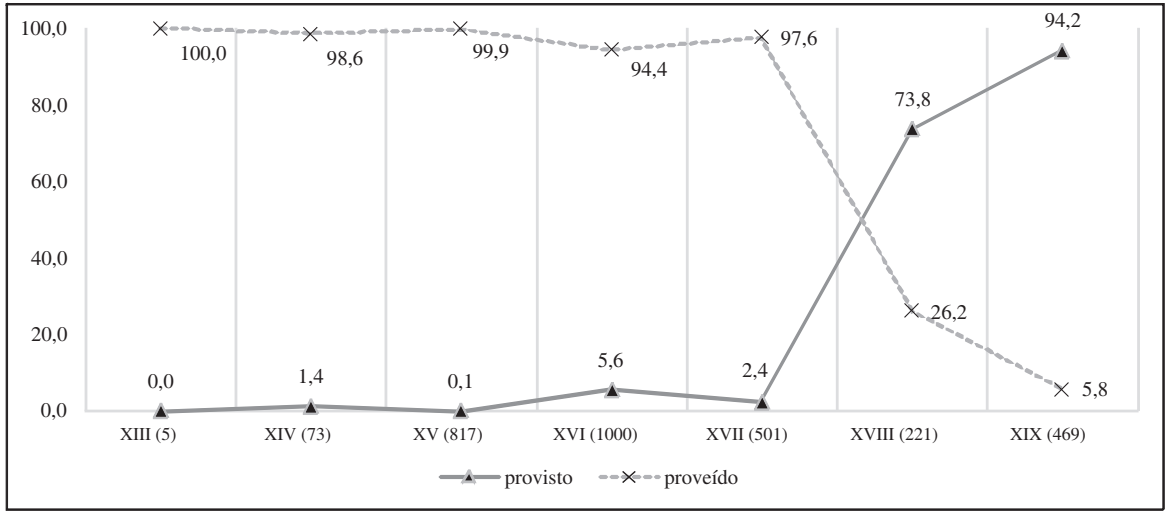

GRÁFICO 2.-Porcentaje de uso de provisto y proveído, siglos XIII-XIX.

En resumen, el comportamiento de los hablantes en torno al siglo XVIII refleja una inversión o radicalización de las tendencias de uso de las variantes de participio de romper y proveer hasta ese momento. Sobresale en el cambio tanto el carácter abrupto en los índices de frecuencia, como la dirección que toma el empleo de las formas de participio; es decir, la variante fuerte, rizotónica, se impone sobre la arrizotónica, "regular", en contra de la tendencia hacia la generalización de formas arrizotónicas en el sistema verbal (cfr. Penny, 2006: 268-271; Malkiel, 1993). Para explorar en más detalle si el cambio se debe a algún factor lingüístico que pasa inadvertido en los índices de frecuencia general, se llevó a cabo una clasificación más detallada de las variantes de participio con el fin de identificar posibles factores significativos como son: las tendencias de los índices de frecuencia según las funciones de uso, la aparición en distintas tradiciones textuales y, en la medida de lo posible, diferencias de uso geolectal.

\subsection{Distribución funcional de los participios de romper y proveer}

Antes de exponer los resultados del análisis, es necesario comentar brevemente la metodología empleada en la clasificación funcional de los participios. Todos los casos se clasificaron de acuerdo con su función en el contexto de la cita: adjetivo (1-2), participio perfectivo (3-4) y participio pasivo (5-6). Estos usos se ejemplifican a continuación con citas del verbo romper en el siglo XVI?

${ }^{9}$ Si no se indica lo contrario, todos los ejemplos provienen del CORDE (Real Academia Española, en línea). 
(1) Ninguno mas astuto ni rompido (1589, Juan de Castellanos, Elegías de varones ilustres de Indias).

(2) y a cabo de un año anda el pobre moço roto, descalço, disoluto (15211543, Fray Antonio de Guevara, Epístolas familiares).

(3) el pueblo avía rompido la salvaguardia del duque (1569-1573, Diego Hurtado de Mendoza, De la guerra de Granada).

(4) En esto el florestero hauia roto el lançón junto al fierro (a1574, Jerónimo de Urrea, Primera parte del libro del invencible caballero don Clarise).

(5) Y fue rompido por el maestre en un rencuentro que tuvieron (1579, Jerónimo Zurita, Anales de la corona de Aragón).

(6) fue roto su exército por los vezinos de la ciudad (1594, Alonso de Villegas, Fructus sanctorum y quinta parte del Flossanctorum).

Conviene matizar que los casos de estructuras en las que el participio se construye con verbos copulativos, ser y estar principalmente (p. ej.: "Fuimos muy bien provistos de muchas gallinas" [1519-1526, Cortés]), se clasificaron en la mayoría de las ocasiones con función adjetival. La inclusión del agente implícito fue el elemento en que nos apoyamos para distinguir el estado ("Estuvimos muy bien provistos") de la voz pasiva ("Fuimos muy bien provistos por $+<$ agente $>$ ") ${ }^{10}$.

Por último, en la clasificación de los participios, se excluyeron varios casos de nominalización. Estos incluyen formas sustantivadas ("suplico declaren si egecutaré lo proveido y mandado en las dichas Aduanas" [1564]), la lexicalización de proveído en el uso técnico de 'resolución judicial' ("auemos por aplicada la quarta parte de todas las condenaciones y penas pecunarias, y proueidos que se hizieren de aqui adelante" [1638]), y la lexicalización de provisto ("si cumplidos los seis meses no hubiese llegado el provisto para él, que en tal caso pudiese prolongar el gobierno del justicia mayor, o nombrar otro con el título de corregidor" [1747] $)^{11}$.

\subsubsection{Rompido y roto}

Desde ese marco metodológico, las tendencias en la distribución de funciones de las variantes de romper se mantienen claramente perfiladas. Así, aunque la

\footnotetext{
${ }^{10}$ En apoyo a nuestra postura consúltense, entre otros, Romani (2008), Sleeman (2011) e Yllera (1999).

${ }^{11}$ La lexicalización de provisto también está ampliamente documentada en el siglo XVIII con 76 de los casi 90 casos recogidos en el CORDE, en la acepción según Autoridades de: "segundo part[icipio] pass[ado] del verbo Proveer que, se usa hablando de la dignidad, ó empleo, que se da á alguno, y de la persona en quien recae" (Real Academia Española, 1737: s.v. provisto). A todas luces, parece tratarse de una nueva - y fugaz - acepción que desaparece de los repertorios lexicográficos ya en el siglo XIX.
} 
forma regular rompido covariaba con la forma etimológica roto, la forma rompido ha sido la forma preferida en construcciones perfectivas desde el siglo XIII hasta el siglo XVII. Los porcentajes incluidos en el gráfico 3 son elocuentes: roto se impone en porcentajes entre el $80 \%$ (siglo XIII) y el 75,3\% (siglo XVI) en funciones adjetivales, mientras que rompido oscila entre el $100 \%$ y el $77,2 \%$ en función verbal en el mismo periodo. Las tornas cambian radicalmente a partir del siglo XVIII cuando roto mantiene las funciones adjetivales en un $95 \%$ de los casos y acapara las funciones verbales en más de un $85 \%$ de los casos del siglo XVIII y en prácticamente la totalidad de la documentación extraída en el siglo XIX (por encima del $98 \%$ ). Estas tendencias se presentan en los gráficos 3 y 4 .

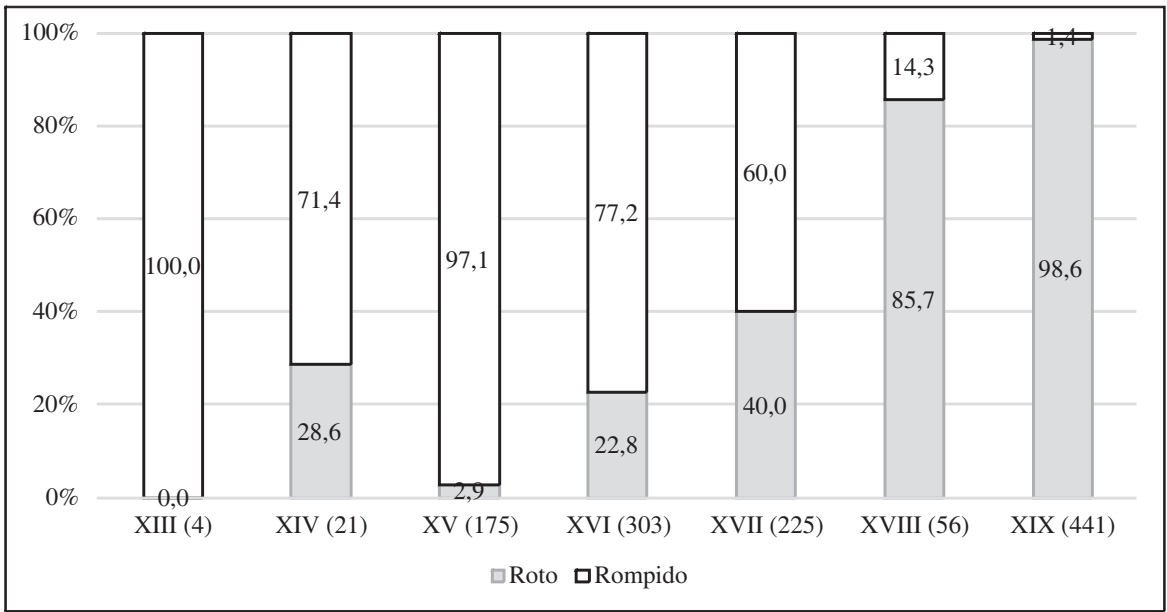

GRÁFICO 3.-Distribución de roto/rompido, función verbal (\%).

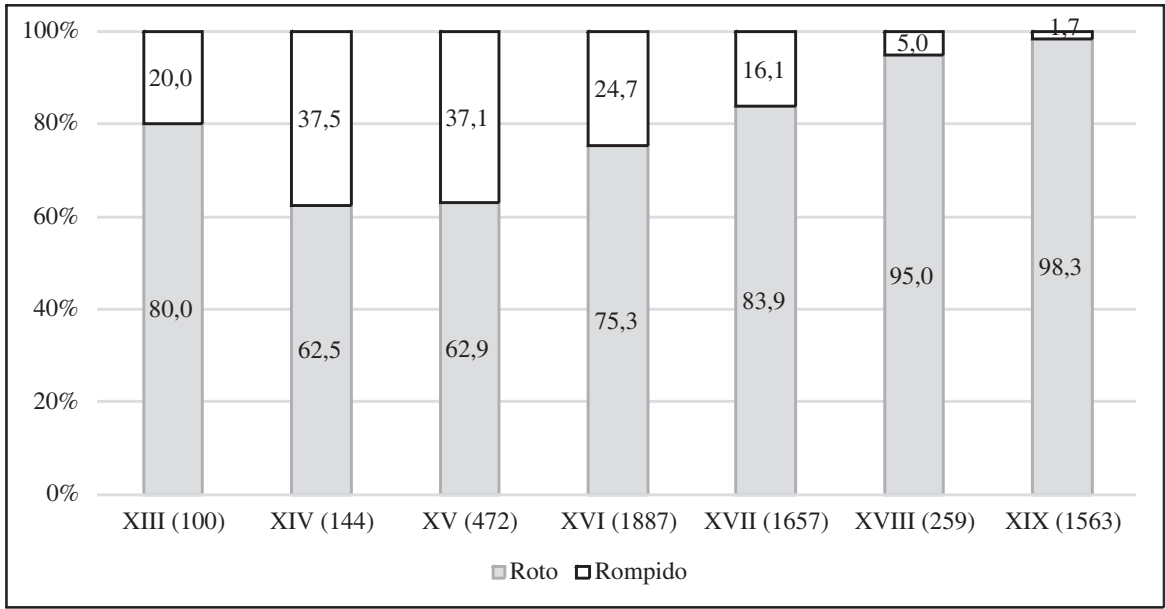

GRÁFICO 4.-Distribución de roto/rompido, función adjetival (\%). 
En términos generales la distribución de uso de ambas formas se extiende en las diferentes tradiciones discursivas. El bloque principal de casos en los siglos XIII y XIV se concentra en tradiciones más alejadas a la inmediatez comunicativa (textos jurídico-administrativos e historiográficos). La extensión de uso a otras tradiciones se constata en los dos millares de casos recogidos desde el siglo XV hasta el siglo XVII en relatos extensos, tratados, vocabularios (de Nebrija y Palencia), obras historiográficas, religiosas, cartas y documentos notariales, composiciones en verso tanto en autores menores como en los consagrados por el canon (Quevedo, Lope de Vega, Fray Bartolomé de las Casas, Alonso de Ercilla, Juan y Alfonso de Valdés, etc.). La diversidad textual y aceptación generalizada de rompido durante estos siglos contrasta con el asentamiento de roto y con la escasísima documentación de rompido a partir del siglo XVIII. Frente al millar de casos de roto, tan solo se recoge una docena de casos de rompido en obras de ocho autores en el siglo ilustrado (en documentos notariales, de poesía y prosa literaria) y una docena más en el siglo decimonónico en 11 obras de contenido histórico (p. ej., Introducción a las Cortes de los antiguos reinos de León y Castilla o la Historia general de Chile) y en boca de personajes de situación sociocultural baja como demuestran las citas (7-8).

(7) iy patas para arriba con medio costillar rompido! Yo los conozco bien a esos condenaos (1890, Acevedo Díaz, Nativa [Uruguay]).

(8) ¡Qué tal que yo no tuviera mis alhajas de oro bien aseguradas en mi caja de fierro! ¡Esta era la hora que ya se las había endonao todas al marchante! Pero nian así: ¡ya me habrán rompido mi caja!... (1896, Carrasquilla, Frutos de mi tierra [Colombia]).

Por último, debe anotarse que la diversidad geográfica de ambas formas se extiende por la Península y a ambos lados del Atlántico a partir del siglo XVI. No obstante, como ya se apuntaba para los casos en el siglo XIX, la restricción de rompido a los estratos sociales menos expuestos a la variedad estándar continuó desde entonces y "[t]odavía se registra hoy en la lengua popular de México y parte de las áreas centroamericana, antillana y andina, pero no ha pasado a la lengua estándar" (Real Academia Española y Asociación de Academias de la Lengua Española, 2009: 244). Volveremos sobre este punto al final de este estudio.

\subsubsection{Proveído y provisto}

Por lo que concierne a las formas de participio del verbo proveer (proveído y provisto), los gráficos 5 y 6 incluyen la distribución por siglo y función. Desde el punto de vista funcional, proveído no restringe su uso a funciones adjetivales o verbales a lo largo de los siglos. Es cierto que el porcentaje de uso en funciones atributivas —en estructuras con verbos copulativos (ser/estar) o semi-copulativos 
(quedar) — es ampliamente superior a usos verbales en tiempos de perfecto o estructuras pasivas. No obstante, su documentación como participio en tiempos compuestos se mantiene constante durante los siglos de mayor uso. Se trata, por tanto, de tendencias estables en las distintas funciones.

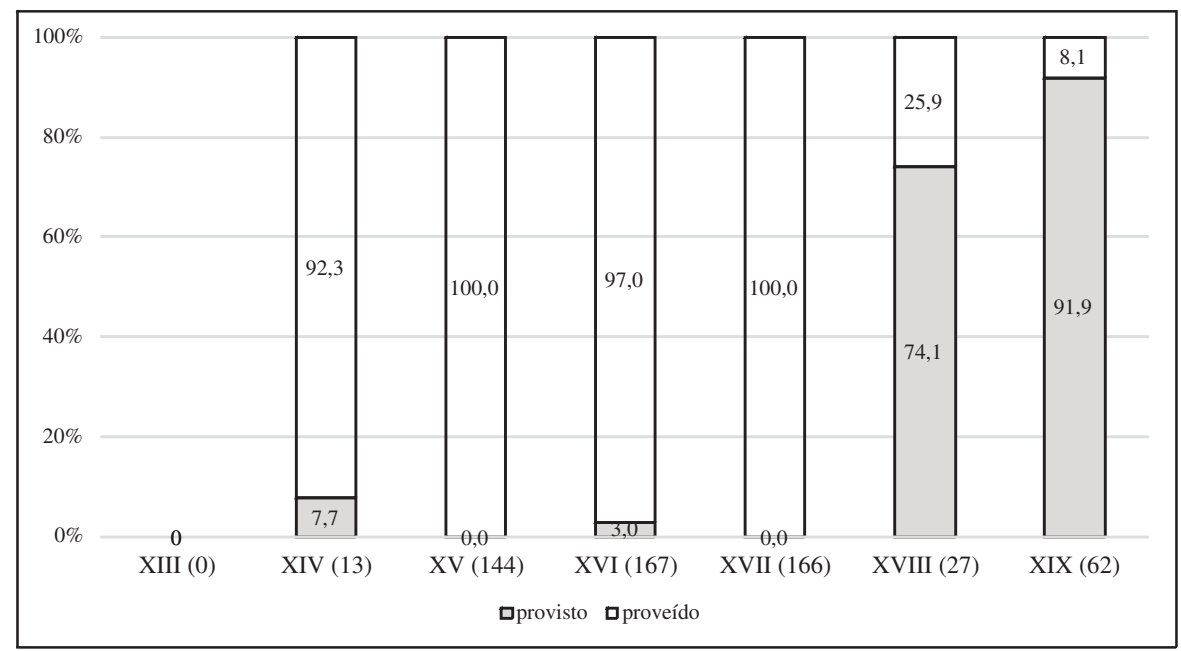

GRÁFICO 5.-Distribución de provisto/proveído, función verbal (\%).

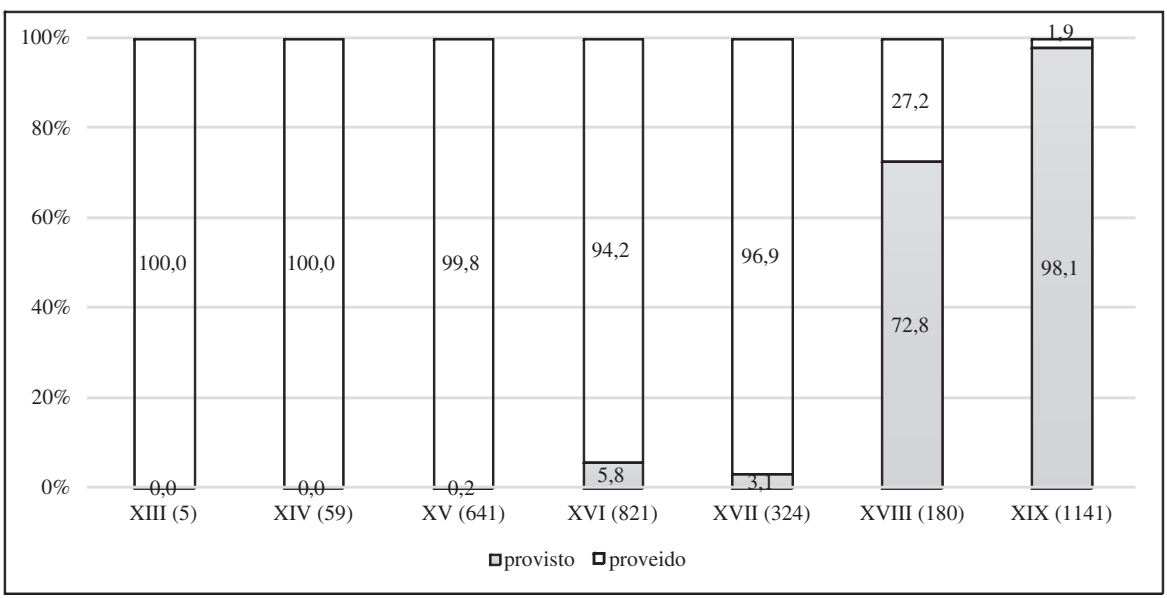

GRÁFICO 6.-Distribución de provisto/proveído, función adjetival (\%).

En relación con su extensión de uso en distintas tradiciones discursivas, el empleo de proveído se asocia con tradiciones alejadas de la inmediatez comunicativa. Así, se recoge con porcentajes muy amplios en textos de carácter jurídico e 
histórico desde sus primeras documentaciones. De manera meramente orientativa, más del $75 \%$ de las manifestaciones en los siglos XIV-XVI provienen de textos jurídicos o históricos. La extensión de uso a otras tradiciones textuales, ya en época moderna, continúa siendo a obras típicamente alejadas del eje de la inmediatez comunicativa, como son las obras de carácter religioso, científico y didáctico.

Por último, en cuanto a la distribución geográfica, más allá de su documentación inicial en textos orientales de la península, no destaca ningún patrón reseñable. Desde el siglo XVI, en el caso del lexema proveído, y desde el siglo XVII respecto a provisto, se documentan variantes a ambos lados del Atlántico.

De lo expuesto hasta el momento pueden extraerse las siguientes conclusiones preliminares. Primero, el comportamiento inicial de las variantes de los participios de romper y proveer mantenía la tendencia esperable en los contextos de convivencia de participio duplo (cfr. Penny, 2006: 268-271; Real Academia Española y Asociación de la Lengua Española, 2009: 244, y, para el contexto románico, Maiden, 2016: 507). Hasta aproximadamente el siglo XVIII, la variación entre las variantes rizotónicas y arrizotónicas era aceptada, según la documentación, si bien era patente una distribución entre las variantes arrizotónicas (rompido y proveído), que dominaban en usos de participio verbal (formación de tiempos compuestos) y las variantes rizotónicas (roto y provisto), que sobresalían en el empleo adjetival. Segundo, la evidencia no muestra indicios de que las formas arrizotónicas hubiesen perdido vigencia a finales del siglo XVII y tampoco ofrece una marcada tendencia de uso a favor de la forma rizotónica. Tercero, no podemos apelar exclusivamente al factor frecuencia. Es decir, podría pensarse que la preferencia por las formas rizotónicas roto y provisto descansase en el índice de frecuencia global. Si nos fijamos en romper, por ejemplo, de los más de 7.000 casos analizados, más del 78 $\%$ (5.618) corresponden a formas de roto. Este dato confirmaría la relevancia de este factor. Sin embargo, cuando nos fijamos en proveer, los más de 3.800 casos examinados se distribuyen claramente a favor de proveído con más de 2.400 frente a los 1.425 de provisto. Se comprueba, por tanto, que la frecuencia no es el factor determinante o, al menos, no es el único ni es explicativo de todos los casos estudiados. En cuarto y último lugar, el análisis refleja en ambos verbos un corte radical en el empleo de las formas arrizotónicas del participio a partir del siglo XVIII. En este contexto, la asociación de este siglo con una posible preferencia prescriptivista de uso que se impusiera especialmente desde el siglo XVIII es una posible vía explicativa a la innovación en el empleo de las formas de participio. En la siguiente sección exploramos esta posible explicación.

\section{LA CODIFICACIÓN DE LAS FORMAS DE PARTICIPIO}

En la sección anterior se ha comprobado que, a pesar de los índices de frecuencia en la distribución de uso en funciones adjetivales o verbales, hasta el siglo 
XVIII los hablantes aceptaban el empleo de una u otra forma indistintamente. En este contexto, cabe preguntarse si existe algún indicio en la tradición historiográfica que apunte una imposición prescriptiva o, en su defecto, el establecimiento o existencia de actitudes en el uso de una de las variantes.

En el recorrido cronológico se han establecido dos parámetros. Uno de carácter temporal con un antes y un después del siglo XVIII, teniendo en cuenta la fundación de la Real Academia Española; y otro parámetro de contenido y uso mediante una clasificación entre obras monolinguies y las elaboradas con propósitos pedagógicos, tanto las bilingües como las monolingües destinadas a la enseñanza, incluidos compendios y tratados de gramática, así como algunos de los hitos lexicográficos de la historia de la lengua. El examen de las obras consultadas revela los distintos esfuerzos en la codificación de la variación o, como se comprobará, la ausencia de estos ${ }^{12}$.

\subsection{Descripción en las gramáticas hasta el establecimiento de la Real Academia Española}

En general, y fijándonos únicamente en los trabajos más relevantes, destaca la escasez de atención que ha recibido este fenómeno y, allí donde se ha comentado, destaca la repetición en la explicación ofrecida. De la Gramática nebrisense, por ejemplo, se entresaca únicamente el comentario puntual en (9), aunque útil para nuestro propósito.

(9) pocos verbos echan el participio del tiempo passado \& el nombre participial infinito en otra manera, como de poner, puesto; de hazer, hecho; de dezir, dicho; de morir, muerto; de veer, visto; aunque su compuesto proveer no hizo provisto, sino proveído; de escrivir, escripto (1989 [1492], lib. v, cap. 11).

Más allá de esta nota, sobre la que volveremos, Nebrija no hace referencia explícita a la frecuencia de uso — salvo en el caso de proveído - y tampoco recoge la distribución de las variantes de los verbos aquí estudiados. Debemos inferir, por tanto, que el participio aceptado de ambos verbos, proveer y romper, era re-

12 En el muestreo de la codificación se consultaron un total de 44 obras. El reparto por siglo fue el siguiente: 7 corresponden a los siglos XV y XVI, 7 al siglo XVII; 9 al siglo XVIII (tres de las cuales fueron elaboradas por la Academia); 15 al siglo XIX, una de las cuales era académica; y 6 al siglo $\mathrm{XX}$, tres de las cuales eran académicas. Por lo tanto, la distribución entre obras académicas y no académicas se reparte en 7 académicas y 37 no académicas. Recordemos que de entre estas últimas se encuentran gramáticas, obras lexicográficas, compendios escolares y de enseñanza del español como segunda lengua. Aunque el examen dista de ser exhaustivo, el objetivo inicial fue un rastreo que ofreciera una muestra representativa de las ideas recogidas en distintos momentos cronológicos sobre el uso y normas en el empleo de los participios escogidos como objeto de estudio. Sin duda, una investigación más amplia de carácter historiográfica, de acuerdo con la ideología del momento, podría arrojar más claridad a los vaivenes sobre el uso de las distintas variantes de los participios. 
gular, es decir, arrizotónico. De los tratados y gramáticas de la siguiente centuria no se encontró apenas ningún comentario sobresaliente acerca de la variación en las formas de participio de ninguno de los verbos que nos ocupa. La anónima Gramática de la lengua vulgar de España, por ejemplo, únicamente indica "en los [verbos] dela tercera [conjugación] hai alguna ecepcion [sic], que la remito al uso" ([Anónimo], 1966 [1559]: 61) ${ }^{13}$.

En lo que concierne al siglo XVII, el Tesoro de la lengua castellana o española de Covarrubias registra en la entrada para romper ejemplos de rompido en uso adjetival ("y como están holgadas y nuevamente rompidas [las tierras], dan los primeros años mucho más fruto que las otras tierras") y al final de la entrada se ofrece también un ejemplo de la variante roto, en una acepción que sugiere un uso sustantivado: "Roto, el que trae el vestido rasgado, de ruptus, a, um" (1611, s.v.). Para la breve entrada de proveer, Covarrubias incluye proveído y su definición: "[p]roveído, el que se percibe en esta forma" (1611, s.v.). En cuanto a gramáticos se refiere, Correas, en su Arte grande de la lengua castellana, ofrece una larga lista de "partizipios formados irregular-mente" e incluye entre paréntesis, cuando existe, la forma regular. Tal es el caso de "comfuso (comfundido), imfuso (imfundido), desdicho (desdezido), contradicho (contradezido), (...) roto (rompido)" (1903 [1626]: 183). De modo general, sin especificar ningún caso, indica sobre estos participios "irregulares": "[a]lgunos pareze qe se podrían tener por simples nombres Adjetivos verbales. Los niños por analogía forman los regulares, i algunas personas por grazia y juguete, i á vezes por descuido sin reparar en mas de dezir su conzeto" (Correas, 1903 [1626]: 184).

De esto se desprende que el participio rizotónico era, a juicio de Correas, el común en la formación de los tiempos compuestos de romper, aunque existían las formas regulares en -ido, mientras que el arrizotónico proveído, sería el esperado (¿y único?) para proveer si se acepta que su lista de verbos "irregulares” es completa $^{14}$. También se establece la tendencia a la generalización de las formas arrizotónicas, disculpadas en los niños durante el proceso de adquisición e implí-

\footnotetext{
13 No se encontró información relevante en otros trabajos consultados. Diálogo de la lengua, por ejemplo, no incluye ningún comentario metalingüístico, aunque en una ocasión emplea el participio proveído como adjetivo: "Valdés: Soy contento. Dizen que yendo camino el Conde de Ureña, y llegando a un lugar mal proveído de bastimentos, mandó a un su mayordomo, que pocos días antes avía recibido, que le tuviese" (Juan de Valdés, 1984 [1535?]: 192 [f. 82v]). Por su parte, ni Útil y breve institution para aprender los principios y fundamentos de la lengua Hespañola impresa por Bartolomé Gravio en Lovaina ([Anónimo], 1977 [1555]) ni Gramática castellana de Cristóbal de Villalón (1558) contienen datos pertinentes a nuestro objetivo.

14 Esto es evidente a partir del comentario con que Correas continúa su descripción y en el que específicamente apunta cinco casos en que el participio regular es el que se emplea en la formación de los tiempos compuestos: "el Partizipio Ministro se usa formado de los Regulares con el verbo he, has, para hazer los rodeos de los tiempos qe se suplen con ellos: ansí he comfundido, has confundido (...) No se dirá he comfuso" (1903 [1626]: 184). La aclaración se extiende para las formas infundido, despertado, desdezido y soltado.
} 
citamente proscritas entre los adultos, pues solo deben ocurrir por descuido o en una situación en la que el empleo de la forma débil tiene el propósito de la risa.

Para encontrar otros testimonios de interés debemos desplazar nuestra atención a las gramáticas bilingües ${ }^{15}$. En los siglos XVI y XVII, periodo que podría considerarse uno de los primeros en la internacionalización del castellano, proliferó el desarrollo de gramáticas y diccionarios destinados a la enseñanza del español. En algún caso, como en las gramáticas de Miranda (1566), Oudin (1606) o Sanford (1611), se llama la atención sobre la formación de participios rizotónicos (de, por ejemplo, soltar, despertar, volver, hacer, poner, ver, abrir, cubrir, decir, escribir, morir), pero no se tratan otras peculiaridades relevantes para nuestro propósito ${ }^{16}$. Una excepción destacable a la ausencia de información, la encontramos en la gramática, en español y francés, de Texeda (1619). En su presentación de los verbos irregulares de la tercera conjugación se advierte: "En España los cortesanos en los preteritos de los verbos escreuir, morir, e imprimir, se siruen de los participios escrito, muerto, e impreso pero los grosseros y villanos se siruen de los participios escriuido, morido, e imprimido" (Texeda, 1619: 258). A este respecto, debe notarse que en la conjugación del verbo romper, Texeda recoge únicamente la forma rompido, lo cual concuerda con el uso más frecuente en la documentación del momento. Se trata, probablemente, del indicio más claro sobre el desarrollo de actitudes linguíísticas hacia la variación en las formas de participio.

En resumen, hasta el siglo XVIII la tradición gramatical examinada es reflejo de los datos globales extraídos del CORDE. Desde Nebrija se confirma la ausencia generalizada de una forma rizotónica en el caso de proveer y el empleo de dos participios de romper, uno fuerte o rizotónico y otro débil o arrizotónico. El recorrido por los principales tratados y gramáticas, ha revelado, además, información cualitativa de notable interés. Al menos desde el siglo XVII se encuentran comentarios moderadamente prescriptivistas en Correas y asociaciones explícitamente positivas hacia el empleo de formas rizotónicas, frente al empleo desprestigiado de formaciones analógicas arrizotónicas en Texeda.

\subsection{Codificación desde el establecimiento de la Academia}

\subsubsection{Gramáticas o compendios académicos}

No cabe duda de que el establecimiento institucional de la Real Academia Española supone un punto de inflexión considerable en la proyección y mante-

15 Un testimonio adicional que menciona ambas formas del participio se encuentra en el Arte de la lengua española reducida a reglas y preceptos de rigurosa gramática: "y los del latino solvo hazen absuelto \&c. romper. roto y rompido" (Villar, 1651: 48).

${ }^{16}$ Para el estudio de ese periodo (siglos XVI a XVIII) se consultaron las obras incluidas en Gómez Asencio (2001). 
nimiento de una norma lingüística. Aun si pensamos que la implementación de cualquier sugerencia dista de ser efectiva y mucho menos inmediata, la actuación y opinión de la institución supone en todo caso una opinión de peso capaz de influir en el uso de variantes lingüísticas o su omisión en determinados registros o estilos en los denominados cambios "desde arriba" (Labov, 1972: 285-296).

Ni la primera empresa académica, comúnmente conocida como Diccionario de autoridades, ni la primera edición de la gramática académica de 1771 ofrecen información dispar a la ya comentada. Con la publicación de una nueva edición de la gramática, a finales de siglo, nos encontramos con una descripción ya anticipada en la primera edición: el empleo excepcional de algunos participios irregulares en tiempos compuestos. La excepción la marcan las formas de los verbos prender, prescribir, proveer y romper, "pues igualmente se puede decir: ha prendido...ha prescribido...ha proveido...ha rompido que ha preso, ha prescrito, ha provisto, ha roto" (Real Academia Española, 1796: 222). Cierto es que ya en esta edición, en las postrimerías del siglo XVIII, se indica, no sin cierta sorpresa, "[y] aun es mas usado roto que rompido" (Real Academia Española, 1796: 222).

Las ediciones posteriores mantienen rompido y proveído como formas posibles junto a las más comunes, aunque "irregulares" de roto y provisto. Sirva la cita en (10) de la trigésimo primera edición (Real Academia Española, 1920: 130) como ejemplo representativo de lo que se recoge también en las ediciones intermedias y en la trigésimo cuarta, y última, de $1931^{17}$.

(10) Estos participios irregulares, tomados más literalmente del latín, sólo se usan como adjetivos, y nunca para formar los tiempos compuestos por medio del auxiliar haber. Exceptúanse los participios irregulares frito, preso, provisto y roto, que se usan como tales y más frecuentemente que los regulares freído, prendido, proveído y rompido.

Por último, el Esbozo de una nueva gramática (Real Academia Española, 1973) ofrece dos puntos de interés. El primero, y en contrapunto a toda la tradición gramatical, se apunta en nota a pie de página un matiz no del todo explicado sobre proveído y provisto: "No son del todo equivalentes. Se dice: Han provisto una vacante y El gobierno ha proveído y proveerá" (1973, 2.12.11) ${ }^{18}$; y el segundo, después de mencionar algunos casos en que el participio débil "acaba eliminando al participio fuerte: expendido a espeso, arrepentido a repiso", reconoce el carácter excepcional de lo sucedido en torno al empleo de las variantes participiales de

17 Se consultaron las ediciones de los compendios de 1887 y 1889 , pero no pudo revisarse el texto de otras ediciones. En todo caso, la repetición de criterios en las ediciones apunta, en principio, una continuidad en ediciones intermedias.

18 Este comentario se hace eco del mismo contraste que años antes había sugerido Bello en relación con el empleo de roto en estructuras transitivas y de rompido en intransitivas. Sobre la incongruencia de ambas líneas de argumentación véase más adelante la sección 3.1. 
romper, también en nota aparte: "[1] contrario ha ocurrido por excepción con roto frente a rompido, aunque rompido no ha dejado enteramente de usarse" (1973, 2.12.11). Para concluir con la revisión de la codificación gramatical, retomamos lo ya indicado al comienzo de este estudio sobre la postura de la Nueva Gramática: el mantenimiento "hasta finales del siglo XVI" del participio regular rompido (2009: 243) y la concurrencia de participios regulares con los irregulares "aunque con notables diferencias en su extensión y en su uso" (2009: 244). Este sería el caso de provisto y proveído.

\subsubsection{Gramáticas o compendios no académicos}

Aunque las obras no académicas del siglo XVIII consultadas no ofrecen cambios importantes a la información presentada en los trabajos académicos, es posible entresacar comentarios relevantes sobre la variación existente en el empleo de las variantes. Así, los autores de gramáticas escolares del siglo XVIII presentan, por ejemplo, rompido y roto como posibilidades para un mismo autor en distintas secciones de su obra. Esto es lo que se observa en los datos extraídos de la gramática del navarro Torre y Ocón, quien, en su entrada del verbo francés rompre, ofrece la forma del participio rompu, glosada como 'roto' (1728: 113114). Sin embargo, en la sección sobre la pronunciación de la ortografía $<$ s $>$ se incluye una traducción para uno de los ejemplos con una forma del participio regular: "aunque en la conversación familiar, quando se dize: Les ponts en sont rompus, se han rompido los puentes" (1728: 21). Otro tanto puede decirse de la gramática de Giral del Pino donde se hallan dos ejemplos del participio en función adjetival, uno de los cuales presenta la forma regular y el otro la irregular: "Mis medias están rotas" 'My flockings have holes' "Hay un punto rompido" 'There is a stitch fallen' (Giral del Pino, 1766: 323). A pesar de la evidencia en apoyo a la variación en las formas de participio, también es posible inferir, por evidencia negativa, que no todos los hablantes compartían las mismas normas de uso. Los Rudimentos de la gramática castellana de Puig cuentan con una descripción de formas irregulares del participio de pretérito donde aparece roto exclusivamente. "de Prender, Prendido, ò Preso; de Resolver, Resolvido, ò Resuelto; de Romper, Roto, de Soltar, Soltado, ò Suelto; de Ver, Visto" (1770: 128). Esta ausencia es significativa, pues, como se desprende de la lista, el autor incluye la variante regular e irregular para otros verbos.

De entre las obras lexicográficas, merece la pena destacar el registro de rompido, roto en el Diccionario castellano de Terreros y Pando: "no obstante que roto es de mas uso; pero le tiene también rompido, como consta, ademas de otras muchas locuciones, de Lope de Veg. [sic]". En el caso de proveer, Terreros y Pando no se decanta por ninguna de las dos variantes registradas en su diccionario: "PROVEIDO, 
part[icipio] pas[ado]; PROVISTO, segundo part[icipio] pas[ado]. proveido, provisto, sust[antivo] lo mismo que mandato, decreto, auto, ó sentencia de Juez" (1788: s. vv.).

Llegados al siglo XIX, la publicación de obras de gramática se prodigó enormemente ${ }^{19}$. Autores como Saqueniza (1832), Noboa (1839), Solano Vitón (1875) o Avendaño (1897), por mencionar solo algunos, se limitan a copiar y seguir lo dicho en los compendios académicos. Comentario aparte merece la Gramática de Salvá (1852), no necesariamente por divergir en este punto de lo dicho en las gramáticas del momento, sino por un breve comentario sobre los "caprichos del uso" que confirman la preferencia de roto sobre rompido:

(11) Los pretéritos irregulares frito, preso, y provisto, son los únicos que pueden usarse con el haber y suplir el pretérito regular: La cocinera habia frito, ó, freido el pescado; Han prendido, ó, preso al condestable; No sé si habrán ya provisto, ó, proveido el empleo. Sin embargo en esto, como en todo, se presentan, para formar escepciones, los caprichos del uso: más me agrada, Me la ha freido $V d$., por me ha engañado, que no, Me la ha frito Vd.: muchísimo más (...) Roto suena mejor que rompido, v.g. Has roto el vaso (Salvá, 1852: 163).

Por último, debe comentarse el apunte de Bello (1887 [1847]). En relación con las formas de participio, Bello indica: "Verbos hai que tienen dos formas para los participios, una regular i otra anómala: Freir: Freido o frito; Matar: Matar o muerto; Prender: Prendido o preso; Proveer: Proveido o provisto; Romper: Rompido o roto" (1887 [1847]: 172). A continuación Bello reflexiona sobre la distribución de usos según la estructura en que aparecen una u otra forma del participio. Así, en torno a las formas de freír, el gramático advierte:

(12) Cuando hai dos formas para los participios, la una regular i la otra anómala, pueden no emplearse indistintamente. Freido i frito se emplean ambos como participio sustantivado (han freído o han frito los huevos), i como participio adjetivo (los huevos han sido freidos o fritos); pero con otros verbos que haber ó ser, es mejor la segunda forma (están fritos) (Bello, 1887 [1847]: 172).

No obstante, al tratar el comportamiento de las formas de romper, el gramático apunta: "Roto es en todos casos mejor que rompido; bien que en las frases en que el verbo romper no admite complemento acusativo parece preferible rompido: ha rompido en dicterios, ha rompido con su amigo, ha rompido por todo" (Bello 1887 [1847]: 172). El comentario es de interés, pues es el único que ofrece un posible argumento interno en la distribución de las formas del verbo, aspecto que se tratará más a fondo en la siguiente sección (§ 3.1).

${ }^{19}$ El contexto de esa proliferación se encuentra en parte en el esfuerzo de política educativa durante este siglo y que culminó en la Ley de Instrucción Pública (conocida como Ley Moyano de 1857). 
Antes de concluir el repaso al tratamiento de las variantes de romper y proveer en las gramáticas, nos detendremos brevemente en un grupo representativo de trabajos destinados a la pedagogía o enseñanza en las escuelas. En lo esencial, se limitaron a parafrasear lo dicho por la Academia. Así, Ballot y Torres comenta: "Los irregulares casi siempre se juntan con el verbo ser (...) Se esceptúan preso, prescrito, roto y provisto, que se pueden igualmente juntar con el verbo haber" (1845: 188) ${ }^{20}$. Vigas Rigay, por último, señala en un comentario parentético la preferencia por roto sobre rompido entre las variantes de romper: "los dos participios de cada uno de los verbos freir, prender, prescribir, proveer y romper, se usan indistintamente en los tiempos compuestos, como Se ha ROTO ó se ha ROMPIDO (en desuso) un plato" (1895: 70).

La única opinión discrepante de las expuestas hasta el momento se encuentra en la Gramática castellana razonada según los actuales conocimientos lingüísticos de Pérez Barreiro: "Según la Academia, pueden hoy usarse freído y rompido; pero la gente encuentra risibles tales formas" (Pérez Barreiro, 1900: 195).

En suma, entre los siglos XVIII-XX la codificación académica mantiene en sus publicaciones la variación entre las formas de participio de romper y proveer. Esta codificación contrasta radicalmente con nuestros datos recogidos en el CORDE. Así, el corpus diacrónico registra el mantenimiento de roto y provisto en función adjetival y un patente ascenso de las formas rizotónicas en función verbal arrinconando el uso de las formas arrizotónicas a índices que rayan en la práctica desaparición de los textos (de nuevo, según el CORDE). Obviamente, la perpetuación ciega en la codificación de la obra académica ignora o refleja un lapso de varias generaciones en plasmar lo que recoge el uso en los textos. Frente al inmovilismo académico, la muestra de gramáticas no académicas refleja un mayor grado de inquietud en la norma de uso y una aproximación a los cambios que se sucedían en ese periodo. Aunque los trabajos consultados sobre la codificación de las formas del participio no recogen ningún índice explícito de las actitudes hacia proveer, para el caso de romper se advierte mayor variación. Algunos gramáticos del dieciocho empleaban en sus ejemplos ambas formas, roto y rompido (p. ej., Torre y Ocón y Giral del Pino); otros, en cambio, únicamente registraban roto (p. ej., Puig) y los lexicógrafos advertían de un mayor uso de roto (cfr. Terreros y Pando), síntoma de una tendencia en la que la variante rizotónica no solo se mantenía, sino que, además, desplazaba (y marginalizaba en el caso de rompido) el uso de las variantes arrizotónicas. En las postrimerías del siglo decimonónico, la forma de rompido debía representar en determinados grupos y usos una forma desprestigiada, "risible" según lo expuesto por gramáticos de fines de dicha centuria.

${ }^{20}$ En la misma línea podría citarse el trabajo de Fossey (1855: 52). 


\section{FACTORES LINGÜÍSTICOS}

Como se indicó en el apartado anterior, la gramática de Bello fue la única de las consultadas en que se planteó una explicación para la distribución de los participios de romper: "en las frases en que el verbo romper no admite complemento acusativo parece preferible rompido: ha rompido en dicterios, ha rompido con su amigo, ha rompido por todo" (Bello, 1887 [1847]: 172). Inspirados por la aseveración del gramático venezolano, regresamos a los datos recogidos entre los siglos XVI y XVIII, y clasificamos los 578 casos de usos verbales de rompido y roto en usos transitivos e intransitivos. Si la hipótesis de Bello se cumple, deberíamos encontrar una tendencia al empleo mayoritario de rompido en usos intransitivos, lo cual reduciría significativamente su rango de uso y explicaría, efectivamente, el éxito de roto sobre rompido. Los resultados se comentan en la siguiente sección ( $\$ 3.1$ ), a la que siguen dos secciones adicionales en las que se tratan los argumentos que podrían aducirse, inicialmente, para explicar la dirección del cambio y preferencias por las formas rizotónicas: el argumento fonológico-semántico ( 3.2) y el argumento morfómico (\$ 3.3).

\subsection{Argumento sintáctico}

El gráfico 7 muestra la distribución en porcentaje de los 207 casos en que la forma roto se construye con estructuras transitivas e intransitivas en los siglos XVI (69 casos), XVII (90 casos) y XVIII (48 casos). A lo largo de los siglos la estructura transitiva es claramente mayoritaria. Por lo que concierne a las estructuras intransitivas, los siglos XVI a XVIII ofrecen un número de casos en construcciones pasivas, usos con la partícula se y otros usos que se corresponden con los citados por Bello. En ningún siglo la frecuencia de uso se aproxima a cifras significativas o por encima de las estructuras transitivas. Otro tanto ocurre con la forma del participio rompido. El conjunto de 371 casos refleja una distribución porcentual similar a la observada para roto con la excepción del siglo XVIII, momento en que el empleo generalizado de la variante arrizotónica en la documentación se restringe a 8 casos en total, 4 con uso transitivo y 4 con uso intransitivo. De forma ilustrativa se incluyen en (13-18) citas representativas de los usos intransitivos empleados con ambas variantes del participio de perfecto.

(13) a una jaula de cuya puerta, que de vieja se había roto, se escapaba un pájaro (1598, Lope de Vega Carpio, La Arcadia).

(14) El qual consta del metro exylabo o de seys sylabas, en el qual descansa después de auer rompido con el acento en la quinta (1596, Alonso López Pinciano, Filosofía antigua poética). 
(15) se dice que han roto ya con el Inglés y que fué, tras ellos (1654-1658, Jerónimo de Barrionuevo, Avisos).

(16) ¡El freno se ha rompido! ¡Procúrate arrojar! (1625, Mejía de la Cerda, Auto sacramental del juego del hombre).

(17) Quando el jugador de manos ve que se ha roto un pedazo del naype elegido, pasa á su quarto (1791, La mágica blanca descubierta).

(18) Pero como se había rompido ya el freno á la obediencia y respeto (1763, [anónimo] Relación de las operaciones del Arzobispo de Manila).

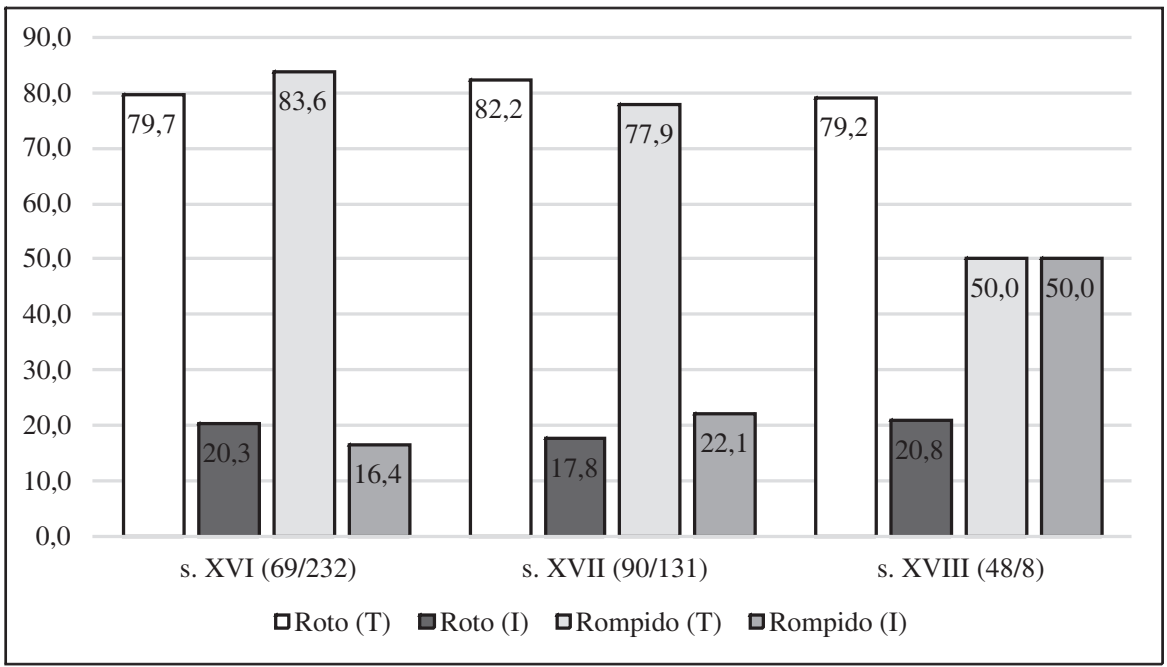

GRÁFICO 7.-Usos transitivos (T) e intransitivos (I) de roto y rompido.

Del examen de los datos se concluye que las dos formas del participio, roto/ rompido, se documentan en las mismas estructuras sintácticas, lo cual no apoya la intuición de Bello. La forma rompido se empleó en índices porcentuales parejos a los de roto tanto en estructuras transitivas como intransitivas hasta su caída en desuso en el siglo XVIII ${ }^{21}$.

\subsection{Argumento fonológico-semántico}

Malkiel (1993) ofrece una respuesta al declive abrupto del participio rompido apoyándose en el fonosimbolismo de la vocal -o y en la semántica de un grupo

21 Aunque no se incluyen los datos por limitación de espacio, nuestro estudio realizó un análisis paralelo sobre las formas de participio proveído y provisto. Los resultados no mostraron tampoco una distribución de funciones en la línea sugerida por Bello. 
de palabras construidas de acuerdo con un mismo patrón formal, $\mathrm{C}_{1} \mathrm{VC}_{2}-o,-a$ (p. ej., bobo, boto, cojo, corto, sordo, tonto). Malkiel sugiere que este esquema fonológico es responsable de la victoria del participio roto, ya que:

(19) en el grupo entero predominaban significados (...) con clara alusión al desmoronamiento, a la dilapidación. En tal contexto roto llevaba una enorme ventaja a rompido; fue esta sugestividad casi fonosimbólica la que, a mi modo de ver, fortaleció la posición medio lábil de roto lo suficiente como para garantizarle la supervivencia en medio de las arremetidas de su rival rompido (1993: 315).

A pesar de su detallado análisis de los datos en el desarrollo histórico de roto, esta hipótesis se enfrenta a serias limitaciones. En primer lugar, la forma de roto se describe exclusivamente en función de adjetivo simple y no se considera su función verbal como participio ni la influencia que otros verbos rizotónicos pudieron ejercer en su mantenimiento (cfr. Lloyd, 1993: 500-501). Además, otro argumento que debilita la hipótesis de Malkiel es el hecho de que, aunque se acepte el fonosimbolismo en la "supervivencia" de roto, no resuelve el caso similar de provisto/proveído donde se reproducen las mismas circunstancias; es decir, la forma fuerte se generaliza en contra del uso mayoritario que ostentaba proveído. Evidentemente, el planteamiento semántico no encaja en este caso y nos llevaría a tener que ofrecer una respuesta distinta (y quizás igualmente adhoc).

\subsection{Argumento morfómico}

Un acercamiento alternativo a la variación de participios y la eliminación de rompido (y proveído) podría formularse desde el principio de "coherencia" típico de la estructura morfómica en el desarrollo de los participios (Maiden, 2018). De acuerdo con la estructura morfómica, la posible alomorfia en el participio se resuelve comúnmente con una distribución de funciones de la misma manera en la inmensa mayoría de casos: usos adjetivales, de un lado, y verbales, de otro. Casos, como el documentado en portugués y siciliano, en que las formas del participio se reparten entre las funciones de participio perfectivo y las de participio pasivo son, parafraseando a Maiden, extremadamente raros (2018: $256)^{22}$. Efectivamente, el comportamiento de las formas de participio es, en ese sentido, 'coherente' en la evolución de los participios de romper y proveer.

${ }^{22}$ La 'coherencia' que caracteriza la alomorfia en el participio se refleja en esta generalización: "Morphological splits in the past participle turn out to be common, but their alignment is typically between 'adjectival' uses and genuinely verbal ones; and these often correspond, moreover, to idiosyncratic semantic distinctions. Alignment of the splits with the distinction between passive and PPTF [periphrastic passive tense forms] is attested, but extremely rare" (Maiden, 2018: 256). 
Ahora bien, aun aceptando las premisas generales de la estructura morfómica, esta no explica por qué en un caso de polimorfismo de participio (coherente) acaba eliminándose prácticamente una de las formas. Tampoco se explica por qué se desarrolló a partir de la forma fuerte (roto y provisto), invirtiéndose la tendencia común, no solo del castellano, sino de la mayoría de las lenguas románicas, de mantener la forma débil en usos de participio perfectivo. Al mismo tiempo, entrando en más detalle, debemos recordar que la clasificación de los usos del participio en estructuras pasivas como estrictamente verbales está expuesta a ciertas complicaciones. La crítica se ha encargado de estudiar el carácter híbrido y el reto en la clasificación del participio en estas estructuras de márgenes borrosos o "fuzzy" (cfr. Romani, 2008; Sleeman, 2011; Yllera, 1999). La consecuencia de esta ambigüedad se refleja en la variación misma con que los hablantes emplean una u otra forma en estos contextos.

\section{FACTORES SOCIALES Y LA FUERZA DE LA ANALOGÍA}

Llegados a este punto, es evidente que ni la codificación en las gramáticas académicas (§ 2) ni la revisión de los factores lingüísticos (§ 3) alcanzan a explicar el declive en el uso de rompido y proveído en nuestro corpus. Debemos, por tanto, volver sobre nuestros pasos y plantear otra vía explicativa a la práctica desaparición del participio analógico desde el siglo XVIII. En este apartado únicamente podemos avanzar la propuesta de trabajo que deberá confirmarse en un examen pormenorizado de los datos en un estudio en progreso. Se trata de una aproximación que combina los factores sociales y los lingüísticos (formaciones analógicas arrizotónicas) en el siglo XVII y su transición hasta el siglo siguiente. Insistimos en que, aunque no se tenga la evidencia positiva en su totalidad en estos momentos, los indicios sobre la necesidad de un planteamiento interdisciplinar en el que se conjugue el análisis y fijación de normas lingüísticas de uso con el cambio de normas culturales en los siglos XVII y XVIII (cfr. Company Company 2015, 2018) arrojará mayor luz y, esperamos, confirmará la hipótesis que planteamos a continuación.

Los indicios, no obstante, son claros. En el ámbito sociolinguiístico se han apuntado en la sección 2 comentarios metalingüísticos que consideramos relevantes para adentrarnos en lo que probablemente era un cambio en marcha a comienzos del siglo XVII y que suponía el reajuste en la evaluación social de las formas analógicas rompido y proveído. En el ámbito lingüístico quedaría por explicar por qué se vieron afectadas las formas arrizotónicas de los verbos objeto de nuestro estudio cuando los argumentos sintácticos, fonológico-semánticos y morfómicos no dan cuentan del cambio. Nuestra explicación se aproxima desde un ángulo distinto, el de la analogía negativa. 


\subsection{La fuerza de la analogía}

La analogía ha sido un mecanismo empleado con asiduidad en la explicación de cambios en morfología verbal. En el desarrollo histórico del español, por ejemplo, la crítica ha aludido a la fuerza analógica en la expansión de nuevos participios arrizotónicos (cfr. Alvar y Pottier, 1983: 279-283; García de Diego, 1961: 253-254; Lapesa, 2000: 774-776; Lloyd, 1993: 498-501; Penny, 2006: 269-271; Ridruejo, 2005). La dirección a favor de las formas arrizotónicas se encuentra en el peso que ejerce la frecuencia de tipos, es decir, del número global de verbos con participio arrizotónico que se impone a verbos con formas etimológicas o rizotónicas, de menor frecuencia (de tipos) y de menor transparencia formal con respecto a las raíces de todo el paradigma verbal (cfr. Fertig, 2013). En (20) se ejemplifica este tipo de analogía a partir de verbos como comer y correr y sus participios comido y curso en el español antiguo.

$$
\begin{aligned}
\text { (20) } & \text { comer }=\text { comido } \\
\text { correr } & =(\text { curso }): \text { corrido }
\end{aligned}
$$

Este cambio analógico responde a casos prototípicos de regularización del participio a los que se aludió en la introducción y cuyo resultado fue la sustitución de la variante etimológica por una nueva forma arrizotónica. Junto a esta tendencia, sostenemos la existencia de otra que actúa negativamente o en dirección opuesta al mantenimiento de variantes arrizotónicas. Este fenómeno es lo que denominaremos analogía negativa y es, a nuestro juicio, el fenómeno que desencadenó el desajuste de normas de uso (o mejor, el reajuste de las actitudes sobre las normas de uso) y sobre el que descansa la caída progresiva de rompido y proveído durante el siglo XVII y su declive abrupto en la siguiente centuria. A diferencia de los casos de regularización, el representado por los casos de romper y proveer demuestra el rechazo de la forma arrizotónica, a pesar de su estabilidad y vigencia histórica. Nuestro argumento se apoya en la influencia que ejerció un grupo reducido de verbos con participios históricamente rizotónicos (p. ej., abierto, puesto, escrito) en el desarrollo de actitudes negativas hacia formaciones analógicas. Lo que se propone, en resumidas cuentas, es que pudo ser el rechazo hacia formas analógicas del tipo abrido, ponido, escribido, etc. (frente a las admitidas en la norma de uso, abierto, puesto, escrito, etc.) lo que acabó por extenderse y afectar a formas aceptadas como rompido y proveído frente a sus correspondientes roto y provisto.

Para analizar el comportamiento de rompido y proveído en el marco de la analogía negativa, es necesario confirmar, primero, que casos como los de abrido y ponido, por tomar unos ejemplos, han estado en relación asimétrica con respecto a las formaciones etimológicas abierto y puesto, las únicas formas aceptables tanto en la documentación disponible como en las gramáticas. Efectivamente, en contraste con la documentación presentada de rompido, el CORDE únicamente 
recoge 3 casos de $a b r i d o^{23}$. Sucede lo mismo con la forma analógica (re)ponido, con menos de 8 ejemplos documentados en el CORDE. Si bien algunas gramáticas, como la de Correas, señalan que las formas abrido y ponido eran formas analógicas posibles, se consideraban inequívocamente como un fenómeno de adquisición, atribuido al mundo infantil, alejado de la norma de uso (como se indicó en $\S 2.1$ ). En definitiva, los ejemplos documentados de estas formas arrizotónicas, cuando aparecen, especialmente desde el siglo XVI, resultan caracterizadoras del habla rústica o burlona ${ }^{24}$. Eso mismo es lo que Correas sugería al identificar quién empleaba las formas arrizotónicas (regulares) de estos verbos: “i algunas personas por grazia y juguete, i á vezes por descuido sin reparar en mas de dezir su conzeto" (Correas, 1903 [1626]: 184). Con menos tacto y más concretamente lo afirmaba Texeda al contrastar el empleo cortesano de los participios escrito, muerto e impreso, mientras que: "los grosseros y villanos se siruen de los participios escriuido, morido, e imprimido" (Texeda, 1619: 258). Coetáneo a estas citas es otro botón de muestra en boca de Benito Repollo, uno de los personajes en un entremés de Cervantes: "Mirad, escribano Pedro Capacho, haced vos que me hablen a derechas, que yo entenderé a pie llano; vos, que sois leído y escribido podéis entender esas algarabías de allende, que yo no" (1615, Retablo de las maravillas). La aparición del participio escribido en la intervención del ignorante alcalde Benito Repollo llama aún más la atención frente a la lengua cuidada de Chirinos, quien claramente representa un grupo social más elevado ${ }^{25}$. Cervantes, junto a otros autores del mismo periodo, se vale así de los participios análogicos como uno de los aspectos lingüísticos para reproducir y caracterizar el discurso oral de los personajes con poca exposición a la variedad prestigiada en el momento ${ }^{26}$.

Conforme a la hipótesis que aquí avanzamos, la difusión de estas actitudes pudo extenderse a otros contextos analógicamente y afectar (en contra o negativamente) a variantes de verbos que, en principio, existían en cierto grado de

${ }^{23}$ Dos de los casos aparecen en composiciones poéticas en rima final de verso. En un caso en versos en cuadernavía del siglo XIII ("ovieron en un rato grant portillo abrido", 1240-1250, Libro de Alexandre), en otro en boca de un pastor: "ya el un ojo tengo abrido" (1525-1547, Farsa racional del libre albedrío); y el tercero es en la obra de Correas.

${ }^{24}$ La tendencia que se expone a continuación coincide plenamente con la ya comentada por Ridruejo (2005) en torno a la actuación de la analogía en los procesos de estandarización en el contexto del asturiano. El proceso de selección de variantes desemboca en ocasiones en el rechazo y estigmatización de algunas formas, que se asocian con la pertenencia a grupos sociales bajos o marginados socioculturalmente (2005: 9).

25 Nos hacemos eco de las palabras de Ridruejo — "Recuérdese el sayagués de las obras dramáticas del siglo XVI" (2005: 9)—y de las apreciaciones de Lapesa, entre tantos otros, sobre la representación de la realidad lingüística que los autores siglodeoristas plasmaban en sus obras a través de los personajes (cfr. Lapesa, 1981: $\$ \$ 72.2$ y 84.2).

26 La unidad bimembre "leído y escribido" se documenta a lo largo de los siglos en el CORDE, siendo nuestra cita de 1605 la primera, con el mismo efecto de caricaturizar lingüísticamente a un personaje crudo, rústico o mal instruido. 
covariación de uso entre las variantes de los participios. Nos referimos, claro está, a los casos de roto/rompido y provisto/proveído. Esta evaluación negativa sería reflejo indirecto del énfasis prescriptivo por respetar y emplear la forma etimológica (irregular) de ciertos verbos, lo cual favorecía las formas rizotónicas de los verbos con participio duplo y rechazaba, por analogía negativa, los casos de abrido, ponido, escribido, y con el tiempo, acrecentaba una posible reticencia hacia el empleo de rompido y proveído. Ciertos hablantes (¿cortesanos?) extendieron las actitudes que existían en los casos de abierto/*abrido, puesto/*ponido a los de roto/rompido y provisto/proveído. Por consiguiente, cabe suponer que durante el periodo del siglo XVII, las formas de rompido y proveído se convirtieron en formas marcadas socialmente y, quizás, estigmatizadas por efecto de la analogía negativa que recibían de la evaluación de verbos con una sola forma de participio (rizotónica) ${ }^{27}$.

Desde la perspectiva aquí avanzada, por tanto, es este fenómeno el que más estrechamente podría vincular la desaparición abrupta de las formas rompido y proveído en la norma de uso del castellano del siglo XVIII con la acaparación de funciones del participio perfectivo rizotónico. En el español contemporáneo la estigmatización del participio arrizotónico de romper queda plenamente establecida, alcanzando los mismos índices de evaluación que otras formas arrizotónicas históricamente no aceptadas en la norma de uso.

En los albores del siglo XX, por ejemplo, encontramos comentarios en gramáticas no académicas que muestran la reacción social hacia rompido: "[s]egún la Academia, pueden hoy usarse freído y rompido; pero la gente encuentra risibles tales formas" (Pérez Barreiro, 1900: 195). Al mismo momento histórico pertenece el texto en (21), entresacado de la obra de Benejam en la que se enseña la conjugación de la forma de participio de romper conjuntamente a la de ver, poner o escribir, entre otros.

(21) El perro ha roto un plato.

¿Dónde está el verbo?... ¿Qué ha hecho el perro? ¿Por qué se dice roto y no rompido?

Conjugad el verbo romper, los tres, tiempos del pretérito perfecto:

Yo he roto. - Yo hube roto. - Yo había roto.

Ahora el verbo ver, poner, cubrir, hacer, morir, escribir, volver, satisfacer, en los mismos tiempos (1904-1905, La escuela práctica: obra destinada a promover la enseñanza primaria moderna mediante ejercicios [España], apud CORDE).

27 En el trabajo en curso se explorará esta hipótesis en detalle incluyendo en el estudio factores coadyuvantes como puede ser la relevancia de los índices de frecuencia de otros verbos, como ver, visto/*veído o el rastreo más detallado de las distintas formas en la representación de distintos registros sociales y culturales. 
Asimismo, la producción literaria del momento se apoya en el empleo de estas formas arrizotónicas de participio para caracterizar el estilo y registro de personajes indoctos y de menor condición social. Una breve muestra de finales del siglo XIX se recogió en las citas de (7-8), repetidas en (22-23) con el participio de romper, a las que añadimos la de (24), ejemplificando el empleo del participio arrizotónico de (re)poner.

(22) Para mí es lo mesmo, señor; y no le saco el bulto a la chuza, ¡de adónde!... Pero, mire patrón que es más fácil romper un tronco con la calavera que amansar con rilaciones un indio... Son el mesmo mandinga para enderezar al cristiano con la picana, y sacarlo por la cola del mancarrón enterito... ¡Siff!... ¡Y patas para arriba con medio costillar rompido! Yo los conozco bien a esos condenaos, que sólo por comerle "la sin hueso" a una vaca la dan contra el suelo... (1890, Acevedo Díaz, Nativa [Uruguay]).

(23) ¡Esta era la hora que ya se las había endonao todas al marchante! Pero nian así: ¡ya me habrán rompido mi caja!... ¡Figuren el tal César... que es hijo de un saltiador, cómo será de ladrón! ¡Allá estará ese bandido usando mis cosas! ¡Hasta llave falsa tendrá pa abrime mis cómodas y mi escaparate, y braciar con todo!... ¡Hasta en mi cama se habrá acostao ese mugroso!... ¡Tan acomedida la puerca, a mandame a temperar!... ¡Pa salir de yo, pa que no les viera las infamias y l'inmoralidá!... (1896, Carrasquilla, Frutos de mi tierra [Colombia]).

(24) Siempre ha sido así, pero ahora con lo que va a haber guerra por esa cuestión de límites se ha puesto peor... ¡Puesto, oí, puesto -se dirigió al sirviente, mientras el teniente llenaba la ficha-; puesto, no ponido, como decís vos! El puesto que tiene don fulano... ¿Caso decís el ponido que tiene don fulano?... Y como decís reponido... Gracias a Dios que hay guerra y que allí van a morir todos los que como vos no son Académicos de la Lengua...Reponido... ¡Repuesto!... ¡Repuesto!... ¡Repuesto!... Trajeron el repuesto, el repuesto del automóvil... (1954, Asturias, El papa verde [Guatemala]).

Las citas en gramáticas y la caracterización de aspectos linguiísticos en la representación de la comunicación oral confirman la devaluación social de rompido y su asignación como variante estigmatizada, alejada de los registros formales y sin limitación geográfica en ese descenso ${ }^{28}$. En definitiva, roto se había establecido para entonces como la única forma aceptable en la norma de uso del español.

${ }^{28}$ Cabe señalar que las variantes analógicas gozan de vitalidad en algunas variedades geolectales del español. En torno a las formas arrizotónicas, en la Nueva Gramática de la Lengua Española se indica: "algunas de ellas siguen hoy vivas en la lengua popular de ciertos países. No obstante, no han pasado a los registros formales y se recomienda evitarlas" (Real Academia Española y Asociación de Academias de la Lengua Española, 2009: § 4.12h). 


\section{Conclusiones}

Este trabajo arrancó con el objetivo fundamental de dar cuenta de un comportamiento inesperado en el desarrollo de la variación de formas del participio perfectivo en castellano: el triunfo de las formas rizotónicas roto y provisto en usos adjetivales y, en contra de lo esperable, en funciones verbales ${ }^{29}$. Efectivamente, el resultado diverge no solo de la tendencia regular, sino que, además en el caso del verbo romper, se produce tras siglos de una situación aparentemente estable en su comportamiento: la forma etimológica roto se emplea en funciones adjetivales, mientras que la analógica, rompido, lo hace mayoritariamente en funciones verbales. Junto a esta tendencia general, destaca un considerable grado de covariación desde el siglo XIII hasta el siglo XVII. Se ha comprobado también que el caso de proveer es distinto en su origen, ya que provisto no se documenta hasta el siglo XV. No obstante, el comportamiento de uso siguió la corriente ya indicada para romper durante los siglos XVI y XVII.

Este comportamiento generalizado en la distribución de funciones hasta el siglo XVII contrasta con la situación analizada en la documentación a partir del siglo XVIII, momento en que las formas rizotónicas en los dos casos objeto de estudio se imponen en funciones de participio verbal. En el análisis de posibles factores que motivaron el cambio, se desechó el argumento sintáctico apuntado por Bello y del que se hizo eco la Real Academia Española (1973). La evidencia demuestra la falta de apoyo a posibles restricciones sintácticas, pues las variantes analógica y etimológica se documentan en usos transitivos e intransitivos ${ }^{30}$. Fue igualmente infructuoso el intento de respuesta ofrecido por Malkiel (1993), en su propuesta desde los planteamientos fono-semánticos, o la posible explicación desde el argumento de 'coherencia' en las propuestas morfómicas (Maiden, 2018). Por último, se tuvo en cuenta la posible influencia que la codificación gramatical pudiera haber ejercido desde el establecimiento de la Real Academia Española. Sin embargo, no se halló evidencia positiva en las gramáticas académicas. Al contrario, sobresale la perpetuación de una norma de inclusión de las formas rompido y proveído frente a la ausencia documental en la época moderna. En definitiva, el desarrollo de las formas de participio de

${ }^{29}$ Lo inesperado de la situación probablemente habría llamado la atención de Menéndez Pidal a juzgar por su predicción: "La tendencia uniformadora se manifiesta en la creación de los participios débiles modernos, en vez de los fuertes arcaicos indicados, y en la admisión de duplicados, como rompido, freído, proveído, que probablemente acabarán por desterrar a los fuertes correspondientes" (1949: 322).

${ }^{30}$ Debe notarse que no siempre es así. Es decir en otras variedades románicas, por ejemplo, se ha documentado cierta especialización en el empleo de sendas variantes, débil y fuerte, en usos verbales (cfr. Maiden, 2016: 507-508). Una especialización de carácter aspectual entre formas débiles y fuertes que aparecían en la formación del pretérito y de los participios se ha estudiado en la historia del inglés (véase, por ejemplo, Cheshire, 1994). 
estos (y otros) verbos en español es atípico y no se ha encontrado una explicación en factores exclusivamente internos.

En respuesta a la ausencia de motivación lingüística se ha propuesto una explicación que integra un posible cambio en la evaluación social de la variación en las formas de participio desde el siglo XVII, momento en que la documentación permite vislumbrar índices significativos en la evaluación social de estas formas. Así, se han aducido comentarios neutrales sobre el "descuido" de algunos hablantes, según indicaciones de Correas, y se han anotado, según Texeda, las divisiones sociolingüísticamente más marcadas sobre el origen "villano" y el "cortesano" en el uso de formas analógicas y etimológicas respectivamente. Este tipo de valoración social reflejaba un comportamiento lingüístico que, sin duda, fue moldeando la conciencia lingüística de los hablantes a favor de las formas fuertes en detrimento de las débiles. Más importante para nuestro argumento es que la valoración debió afectar no solo a casos en que se generaban por descuido (v. gr. escribido, ponido, volvido, etc.), sino a otros que históricamente habían sido - y eran — admitidos por la comunidad de hablantes ( $v$. gr. rompido y proveído). La innovación, probablemente impulsada entre miembros de los grupos medios de la sociedad, debió extenderse gradualmente durante el siglo XVII hasta su generalización en el siglo posterior, de acuerdo con la documentación analizada. A medida que se extendía la preferencia por roto, la reinterpretación ideológica debió hacerse cargo de la adscripción de la variante rompido a usos informales e iletrados. Así, de ser forma admitida, rompido pasaría a considerarse un descuido, una forma villana y, finalmente, una forma risible como apuntaba Pérez Barreiro en los aledaños del siglo XIX. Curiosamente, ajena a esta transformación, la gramática académica perpetuó una tolerancia hacia la variación, o al menos un reconocimiento de esta, aunque de forma asistemática (rompido se desecha, mientras que proveído se mantiene, muy a duras penas).

Para captar este fenómeno de redistribución en el eje social de las formas del participio regular e irregular hemos acuñado la noción de analogía negativa con la que intentamos describir casos, como el presente, en que la prescripción sobre creaciones analógicas se despliega en un curioso caso de hipercorrección con efectos sobre formas admitidas por la norma de uso del momento. El intento del hablante por evitar una forma desprestigiada debió ser el ímpetu que desplazó, sin necesidad fonética, morfosintáctica o semántica, una forma por otra. A través del cambio lingüístico analizado aquí, las formas rompido y proveído parecen ser víctimas de la valoración inequívocamente prestigiada de participios rizotónicos como dicho, abierto, vuelto, puesto, etc. (piénsese en este sentido en la precaria evaluación social en que se encuentra freído, a pesar de su aceptación académica).

En suma, la tensión entre variantes analógicas y etimológicas y su distribución funcional en las categorías de participio y adjetivo nos ha servido para examinar un caso más de la constante interacción entre los factores lingüísticos y sociales 
en el establecimiento de normas lingüísticas y culturales que regulan el uso y valoración de unas u otras formas en la comunidad a lo largo de su historia.

\section{FUENTES PRIMARIAS}

[Anónimo] (1977 [1555]): Útil y breve institution para aprender los principios y fundamentos de la lengua Hespañola. Lovaina. Edición y estudio de Antonio Roldán, Madrid, CSIC.

[Anónimo] (1966 [1559]): Gramática de la lengua vulgar de España. Lovaina. Edición y estudio de Rafael de Balbín y Antonio Roldán, Madrid, CSIC.

Avendaño, Joaquín (1897): Elementos de gramática castellana: precedidos de unas ligeras nociones de lingüística y seguidos de algunas de literatura, retórica y poética, Madrid, Librería Hernando y Compañía.

Ballot y Torres, José Pablo (1845): Gramática de la lengua castellana: dirigida a las escuelas, Barcelona, Juan Francisco Piferrer, imp[resor].

Bello, Andrés (1887 [1847]): Gramática de la lengua castellana, destinada al uso de los americanos. 14. ${ }^{\text {a }}$ ed., Madrid, Librería de Leocadio López.

Correas, Gonzalo (1903 [1626]): Arte grande de la lengua castellana, Madrid, [s. n.] [apud Gómez Asencio 2001]

Fossey, Mathieu de (1855): Compendio de gramática castellana, con anotaciones para la ilustración de los profesiones [sic] de primeras letras, Guanajuato, Tip. Juan Evaristo Oñate.

Giral del Pino, H[ipóli]to San Joseph (1766): A New Spanish Grammar, or, the Elements of the Spanish Language, London, J. Nourse.

Miranda, Juan de (1566): Osservationi della lingua castigliana, Vinegia, Gabriel Giolito de Ferrari [apud Gómez Asencio 2001].

Nebrija, Antonio de (1989 [1492]): Gramática de la lengua castellana. Estudio y edición de Antonio Quilis, Madrid, Centro de estudios Ramón Areces.

Noboa, A. M. de (1839): Nueva gramática de la lengua castellana: según los principios de la filosofía gramatical, Madrid, Imp[renta] de Don Eusebio Aguado.

Oudin, Cesar (1606): Grammaire espagnolle expliquée en françois, Paris, Marc Orry [apud Gómez Asencio 2001].

Pérez Barreiro, Rafael (1900): Gramática razonada según los actuales conocimientos lingüísticos. 2. ${ }^{\text {a }}$ ed. corregida, La Coruña, Imprenta de Viuda de Ferrer e hijo.

Puig, Salvador (1770): Rudimentos de la gramática castellana, Barcelona, Thomas Piferrer.

Real Academia Española (1737): Diccionario de la lengua castellana..., tomo V, Madrid, Real Academia Española.

Real Academia Española (1771): Gramática de la lengua castellana, Madrid, Joachin Ibarra.

Real Academia Española (1796): Gramática de la lengua castellana, 4. ${ }^{a}$ ed., Madrid, Viuda de D. Joachin Ibarra.

Real Academia Española (1870): Gramática de la lengua castellana. Nueva edición, corregida y aumentada, $12^{\mathrm{a}}$ ed., Madrid, M. Rivadeneyra.

Real Academia Española (1920): Gramática de la lengua española, 31. ${ }^{\mathrm{a}}$ ed., Madrid, Real Academia Española.

Real Academia Española (1931): Gramática de la lengua española, 34. ${ }^{a}$ ed., Madrid, Espasa-Calpe.

Real Academia Española (1973): Esbozo de una nueva gramática de la lengua española, Madrid, Espasa-Calpe.

Salvá, Vicente (1852): Gramática de la lengua castellana según ahora se habla, 9. ed., Paris, Librería de Garnier Hermanos, sucesores de D. V. Salvá, México, Librería de José María Andrade. 
Sanford, John (1611): An entrance to the Spanish tongue, London, Th. Haueland [apud Gómez Asencio 2001].

Saqueniza, Jacobo (1832): Gramática elemental de la lengua castellana: con un compendio de ortografía, Madrid, Imp[renta de] Don Norberto Llorenci.

Solano Vitón, Pablo (1875): Gramática castellana: distribuida en secciones y grados conforme al programa publicado por el mismo autor, Valencia, Salvador Amargos.

Terreros y Pando, Esteban (1788): Diccionario castellano con las voces de ciencias y artes, Madrid, Viuda de Ibarra, hijos y compañía.

Texeda, Jerónimo de (1979 [1619-1629]): Gramática de la lengua española, edición y estudio de Juan M. Lope Blanch, México, Universidad Nacional Autónoma de México, Instituto de Investigaciones Filológicas, Centro de Lingüística Hispánica.

Torre y Ocón, Francisco de la (1728): Nuevo Méthodo, breve, útil y necesario para aprender a escribir, entender, y pronunciar las dos principales Lenguas, Española y Francesa, Madrid, Juan de Ariztia.

Valdés, Juan de (1984 [1535?]): Diálogo de la lengua, Esplugues de Llobregat, Plaza \& Janés.

Vigas Rigay, Francisco de A. (1895): Programas para los aspirantes al magisterio de $1^{a}$ enseñanza: gramática castellana, Barcelona, Imprenta de Collazos y Tasis.

Villalón, Cristóbal de (1558): Gramática castellana: Arte breve y compendiosa para saber hablar y escrevir en la lengua Castellana congrua y decentemente, Anvers, Casa de Guillermo Simon [apud Gómez Asencio 2001].

Villar, Juan (1651): Arte de la lengua española reducida a reglas y preceptos de rigurosa gramática, Valencia, Francisco Verengel [apud Gómez Asencio 2001].

\section{BIBLIOGRAFÍA}

Alvar, Manuel y Bernard Pottier (1983): Morfología histórica del español, Madrid, Gredos.

Bosque, Ignacio (1999): "El sintagma adjetival. Modificadores y complementos del adjetivo. Adjetivo y participio", en Ignacio Bosque y Violeta Demonte (dirs.), Gramática descriptiva de la lengua española, Madrid, Espasa-Calpe, vol. I, pp. 217-310.

Cheshire, Jenny (1994): "Standardization and the English Irregular Verbs", en Dieter Stein e Ingrid Tieken-Boon van Ostade (eds.), Towards a Standard English 1600-1800, Berlin, Mouton de Gruyter, pp. 115-133.

Company Company, Concepción (2015): "Continuidades y discontinuidades en la periodización sintáctica del español. La evidencia del siglo XVII", en José María García Martín (dir.), Actas del IX Congreso Internacional de Historia de la Lengua Española, Madrid/Frankfurt, Iberoamericana/Vervuert, vol. I, pp. 717-734.

Company Company, Concepción (2018): "Estandarización cultural y marginalidad lingüística. El siglo XVII: Una gran paradoja en la historia de la lengua española", Études Romanes de Brno, 39, pp. 15-38, <https://doi.org/10.5817/erb2018-2-2>.

CORDE = Real Academia Española: Banco de datos [en línea]: Corpus diacrónico del español, $<\mathrm{http}: / /$ www.rae.es $>$.

CORDIAM = Academia Mexicana de la Lengua (2015): Corpus Diacrónico y Diatópico del Español de América, México, D.F., Academia Mexicana de la Lengua.

Embick, David (2004): "Remarks on the Structure of Resultative Participles in English", Linguistic Inquiry, 35 (3), pp. 355-392.

Fertig, David (2013): Analogy and Morphological Change, Edinburgh, University Press.

García de Diego, Vicente (1961): Gramática histórica española. Segunda edición, Madrid, Gredos.

Gómez Asencio, José Juan (comp.) (2001): Antiguas Gramáticas del Castellano, Madrid, Fundación Histórica Tavera, cd-rom. 
González Pérez, Rosario (2008): "El tratamiento lexicográfico de los participios de pasado de los verbos con doble participio en español", en Dolores Azorín Fernández, Belén Alvarado Ortega, Jaume Climent de Benito, M. Isabel Guardiola i Savall, Ruth M. Lavale Ortiz, Carmen Marimón Llorca, José Joaquín Martínez Egido, Xose A. Padilla García, Herminia Provencio Garrigós, Isabel Santamaría-Pérez, Larissa Timofeeva Timofeev y Elena Toro Lillo (coords.), El diccionario como puente entre las lenguas y culturas del mundo: actas del II Congreso Internacional de Lexicografía Hispánica, Alicante, Biblioteca Virtual Miguel de Cervantes, pp. 247-252, <http://www.cervantesvirtual.com/nd/ark:/59851/bmcvq3g5>.

Labov, William (1972): Sociolinguistic Patterns, Pennsylvania, University of Pennsylvania Press.

Lapesa, Rafael (1981): Historia de la lengua española, 9. ${ }^{a}$ ed., Madrid, Gredos.

Lapesa, Rafael (2000): Estudios de morfosintaxis histórica del español, volumen 2, Madrid, Gredos.

Laurent, Richard (1999): Past Participles from Latin to Romance, Berkeley, University of California Press.

Lloyd, Paul M. (1993): Del latín al español. Fonología y morfología históricas de la lengua española, Madrid, Gredos.

Maiden, Martin (2016): "Inflectional Morphology", en Adam Ledgeway y Martin Maiden (eds.), The Oxford Guide to the Romance Languages, Oxford, Oxford University Press, pp. 497-512.

Maiden, Martin (2018): The Romance Verb: Morphomic Structure and Diachrony, Oxford, Oxford University Press.

Malkiel, Yakov (1993): "Español roto frente al francés rompu", en Johannes Kramer y Guntram A. Plangg (eds.), Verbum romanicum: Festschrift für Maria Iliescu, Romanistik in Geschichte und Gegenwart 28, Hamburg, Bushe, pp. 311-315.

Menéndez Pidal, Ramón (1949): Manual de gramática histórica española, 22. a ed., Madrid, Espasa Calpe.

Penny, Ralph (2006): Gramática histórica del español. Edición actualizada, Barcelona, Ariel.

Real Academia Española y Asociación de Academias de la Lengua Español (2009): Nueva Gramática de la Lengua Española, Madrid, Espasa.

Ridruejo, Emilio (2005): "La analogía en los procesos de estandarización de las lenguas. El ejemplo del asturiano", Lletres asturianes. Boletín Oficial de la Academia de la Llingua Asturiana, 90, pp. 7-23.

Romani, Patrizia (2008): "La ambigüedad de haber + participio y ser + participio en el castellano medieval", en Concepción Company Company y José Moreno de Alba (eds.), Actas del VII Congreso Internacional de Historia de la lengua española, Madrid, Arco/Libros, pp. 1073-1085.

Sleeman, Petra (2011): "Verbal and Adjectival Participles: Position and Internal Structure", Lingua, 121 (10), pp. 1569-1587, <https://doi.org/10.1016/j.lingua.2011.05.001>.

Sleeman, Petra (2014): "From Participle to Adjective in Germanic and Romance", en Petra Sleeman, Freek van de Velde y Harry Perridon (eds.), Adjectives in Germanic and Romance, Amsterdam, John Benjamins, pp. 171-197.

Wasow, Thomas (1977): "Transformations and the Lexicon", en Peter W. Culicover, Thomas Wasow y Adrian Akmajian (eds.), Formal Syntax, New York, Academic Press, pp. 327-360.

Yllera, Alicia (1999): "Las perífrasis verbales de gerundio y participio", en Ignacio Bosque y Violeta Demonte (eds.), Gramática descriptiva de la lengua española, Madrid, Espasa, vol. II, pp. 3392-3439.

Fecha de recepción: 23 de diciembre de 2019

Fecha de aceptación: 24 de marzo de 2020 
